\title{
Relationship between visual status and functional status and the risk of falls in women. The RAC-OST-POL study
}

\author{
Wojciech Rokicki ${ }^{1}$, Bogna Drozdzowska², Aleksandra Czekajło ${ }^{3}$, Władysław Grzeszczak", \\ Katarzyna Wiktor ${ }^{5}$, Wojciech Majewski ${ }^{6}$, Wojciech Pluskiewicz ${ }^{7}$
}

\author{
'Department and Clinic of Ophthalmology, School of Medicine, Medical University \\ of Silesia, Katowice, Poland \\ 2Department of Pathomorphology, School of Medicine with the Division of Dentistry, \\ Medical University of Silesia in Katowice, Zabrze, Poland \\ ${ }^{3}$ Department of Nephrology, Raciborz, Poland \\ ${ }^{4}$ Department and Clinic of Internal Diseases, Diabetology and Nephrology, School \\ of Medicine with the Division of Dentistry, Medical University of Silesia in Katowice, \\ Zabrze, Poland \\ ${ }^{5}$ KCR S.A., Warsaw, Poland \\ ${ }^{6}$ Radiotherapy Department, Maria Sklodowska-Curie Memorial Cancer Center and \\ Institute of Oncology, Gliwice Branch, Poland \\ ${ }^{7}$ Department and Clinic of Internal Diseases, Diabetology and Nephrology - \\ Metabolic Bone Diseases Unit, School of Medicine with the Division of Dentistry, \\ Medical University of Silesia in Katowice, Zabrze, Poland
}

Submitted: 8 December 2014

Accepted: 31 January 2015

Arch Med Sci 2016; 12, 6: 1232-1238

DOI: $10.5114 /$ aoms.2015.55146

Copyright @ 2016 Termedia \& Banach

\section{Abstract}

Introduction: Falls in elderly women producing fractures are a public health problem that could be largely preventable. The aim of this study was to determine the effect of visual impairment on functional status, falls and fractures in women.

Material and methods: We examined 623 women aged $\geq 55$ years in order to assess the association between visual status and functional status and the risk of falls and fractures. Distance, near visual acuity, and depth perception were examined. Functional status was assessed using the Instrumental Activities of Daily Living (IADL) and Timed Up and Go (TUG) tests. The history of falls in the last 12 months and prior osteoporotic fractures were recorded. Results: The mean age of participants was $66.01 \pm 7.76$ years. Distance visual acuity was correlated $(r=-0.13, p<0.0001)$ with an increased number of falls. The most prognostic fall factor was IADL $(Z=3.19, p<0.05)$, which showed a significant association with distance acuity $(r=0.27, p<0.0001)$. The TUG test time significantly increased with diminishing visual acuity: $10.6 \pm 3.1 \mathrm{~s}$ for good, $12.8 \pm 6.1 \mathrm{~s}$ for moderate and $15.3 \pm 8.8 \mathrm{~s}$ for poor visual acuity ( $p<0.0001$, ANOVA 24.4). The IADL also differs significantly $(p<0.0001)$ in subgroups divided according to visual acuity $(23.6 \pm 1.5,22.6$ $\pm 2.9,21.2 \pm 4.8$ points, respectively). In multivariate logistic regression on probability of falls including IADL, TUG and visual acuity, IADL was found to be an independent prognostic factor $(p=0.025)$. The data revealed no association of refractive correction, depth perception, or near visual acuity with fall incidence or history of fractures.

Conclusions: Visual acuity influences functional status and number of falls in women aged over 55 years.

Key words: vision, fall, Instrumental Activities of Daily Living, women.

\author{
Corresponding author: \\ Wojciech Rokicki MD \\ Department of \\ Ophthalmology \\ Medical University of Silesia \\ 35 Ceglana St \\ 40-514 Katowice, Poland \\ Phone: +48 323581227 \\ Fax: +48 322518473 \\ E-mail: \\ wojtek.rokicki@gmail.com
}




\section{Introduction}

The increasing number of elderly people in advanced countries dramatically raises the prevalence of injuries caused by falls [1]. Bone fractures and especially hip fractures [2], the most common injuries among older adults, dramatically raise costs of healthcare systems [3]. Especially older women are at greater risk of falls and fractures than the general population, due to the combination of decreased dexterity [4] and osteoporosis [5].

Although the risk of falls is usually multifactorial [6], vision disturbances such as reduced visual acuity, contrast sensitivity and visual field play a leading cause [7]. Moreover, the prevalence of hip fracture was significantly linked to vision impairment in older adults [8].

The aim of this study was to determine the effect of visual impairment on functional status, falls and fractures among women aged $\geq 55$ years.

\section{Material and methods}

The current study is a part of the RAC-OSTPOL study. RAC-OST-POL concerns several points of bone metabolism and bone status (clinical risk factors, diet, functional status, vision, bone densitometry), and its general aim was to present an epidemiological description in a representative sample of women in regards to risk of osteoporosis and osteoporotic fractures. A study was performed in an epidemiological sample of a whole population of women older than 55 years from Raciborz district, southern Poland. Six hundred and twenty-three women $\geq 55$ years were randomly recruited from the general population of the district. Using postal mail, women received a letter and brochure inviting them to participate in the study. All investigations including vision measurements were performed in May 2010.

The baseline epidemiology data from the RAC-OST-POL study were described previously [9], and in other manuscripts, some aspects including nutrition [10], functional status [11], and the role of education, marital status, occupation or residence [12] were presented.

The study protocol was accepted by the Ethics Committee of the Medical University of Silesia, Katowice, Poland. Each woman before participation in the study gave written informed consent. All procedures followed were in accordance with the ethical standards of the responsible committee on human experimentation (institutional and national) and with the Helsinki Declaration of 1975, as revised in 2008.

Age, weight, height and body mass index (BMI) were recorded for each participant. Women were asked the date of the last ophthalmic examination in a questionnaire. Daily functioning vision acui- ty (with correction if it was at the time of a fall) was measured under standard illumination at 5 meters with Snellen charts. Visual acuity was classified as good: $\geq 0.8$, moderate: $0.7-0.3$ and poor: $\leq 0.2$. A reading test was performed using a Near Vision Acuity Chart. The joint performance of both eyes was analyzed (mainly determined by the better eye). Type of glasses, if used, was recorded for each participant. Stereopsis was measured using a Randot Butterfly Stereotest carried out at $40 \mathrm{~cm}$ with constant illumination. Using clinical judgment, the principal cause of visual impairment or blindness for each eye was determined as described in our previous publication [13].

The diagnosed less affected eye was used for analysis. Functional status was assessed using the Timed Up and Go (TUG) test [14] and the Lawton Instrumental Activities of Daily Living (IADL) test [15]. TUG in the version modified by Podsiadlo and Richardson is a brief assessment of gait and balance. From a sitting position, the patient was asked to stand, walk $3 \mathrm{~m}$ then turn around, walk back to the chair, and sit. The instructions were to walk (not run) as quickly but as safely as possible. Every woman had one practice trial, and the second trial was timed. A result below $10 \mathrm{~s}$ indicates normal mobility. Time of performance above $10 \mathrm{~s}$ indicates increasing problems with gait and balance with a consequence of an increased risk of falls [16].

The IADL test by Lawton was used to assess independence. IADL is a geriatric scale that provides a quantitative assessment of the patient's ability to perform activities of daily living. There are eight domains of function measured in this scale: ability to use a telephone, shopping, food preparation, housekeeping, laundry, mode of transportation, responsibility for own medications and ability to handle finances. The test is scored from 8 points (very low function, dependent) to 24 points (high function, independent). A detailed IADL Questionnaire Design is attached as an appendix.

The history of falling and injuries in the previous 12 months was collected. Each participant was questioned about falls, location of falls and osteoporotic fractures. Osteoporotic fractures were classified as those that occurred as a consequence of a fall from a standing height or less after the age of 40 years.

\section{Statistical analysis}

All analyses were performed using Statistica 7.0 PL. The Shapiro-Wilk test was used to check for normality of distribution of the analyzed factors. Because the dose distribution was mainly not normal, non-parametric tests were applied.

Correlation was calculated with Spearman's test. The differences between groups with respect 
to the analyzed factors were assessed with the Mann-Whitney and Kruskal-Wallis test. To compare the differences in the incidence rates between groups the $\chi^{2}$ test was used. To estimate the probability of a dichotomous endpoint (i.e. fall, fracture) with respect to selected variables, univariate and multivariate logistic regression was performed. All analyses employed a 0.05 significance level.

\section{Results}

Six hundred twenty three women who participated in the RAC-OST-POL study were recruited for ophthalmic examinations. The mean age was $66.01 \pm 7.76$ years (range 55 to 92). Among the women studied, five were still pre-menopausal. Table I presents demographics and baseline health characteristics of the examined group. The number of women who reported one or more falls during the last 12 months was 209. Among fallers, $10(4.78 \%)$ reported fall-related fractures.

The mean dexterity expressed with the TUG was $11.38 \pm 4.58 \mathrm{~s}$.

The average IADL points scored by participants were $23.24 \pm 2.22$. Both tests were significantly correlated with age $(r=0.52, p<0.0001$ and $r=-0.37, p<0.0001$, respectively). The dexterity was also modulated by BMI - the correlation was significant but not so strong as compared with the age factor (for TUG $r=0.16, p<0.0001$ and for IADL $r=-0.10, p<0.0001)$. TUG and IADL tests correlated with each other $(r=-0.47, p<0.0001)$.

The mean visual acuity was $0.8 \pm 0.25$.

Subgroups with good, moderate and poor visual acuity comprised 417 (67\%), 186 (30\%) and 20 (3\%) women, respectively. Comparison of selected parameters between visual subgroups is shown in Table II. Distance visual acuity significantly diminished with age $(r=-0.43, p<0.0001)$. In the examined group, 381 (61\%) women used no spectacles, 196 (31\%) women used glasses with positive lenses, 43 (7\%) with negative lenses, and 3 (1\%) with bifocal lenses, when the reported falls occured.

The mean near vision acuity was D $0.83 \pm 0.71$. Diminished depth perception was recorded in 245 (39.32\%) women. The TUG test time significantly increased with the decrease in visual acuity: $10.6 \pm 3.1 \mathrm{~s}$ for good, $12.8 \pm 6.1 \mathrm{~s}$ for moderate, and $15.3 \pm 8.8 \mathrm{~s}$ for poor visual acuity ( $p<0.0001$, ANOVA 24.4).

The IADL also differed significantly $(p<0.0001)$ in visual subgroups $(23.6 \pm 1.5,22.6 \pm 2.9,21.2$ \pm 4.8 points, respectively).

Table I. Demographic and health characteristics of examined group

\begin{tabular}{|c|c|c|c|c|c|c|}
\hline $\begin{array}{l}\text { Participants } \\
N=623\end{array}$ & \multicolumn{3}{|c|}{$\begin{array}{c}\text { Rural } \\
44 \%(275)\end{array}$} & \multicolumn{3}{|c|}{$\begin{array}{c}\text { Urban } \\
56 \%(348)\end{array}$} \\
\hline \multirow[t]{2}{*}{$66 \pm 7.76$} & \multicolumn{3}{|c|}{$\begin{array}{c}\text { Rural } \\
65 \pm 8.13\end{array}$} & \multicolumn{3}{|c|}{$\begin{array}{l}\text { Urban } \\
66 \pm 7.44\end{array}$} \\
\hline & \multicolumn{6}{|c|}{ NS } \\
\hline $\begin{array}{l}\text { Education } \\
N=623\end{array}$ & \multicolumn{2}{|c|}{$\begin{array}{l}\text { Higher } \\
8 \%(50)\end{array}$} & \multicolumn{2}{|c|}{$\begin{array}{l}\text { Secondary } \\
31 \%(193)\end{array}$} & \multicolumn{2}{|c|}{$\begin{array}{c}\leq \text { Elementary } \\
61 \%(380)\end{array}$} \\
\hline \multirow[t]{2}{*}{$\begin{array}{l}\text { Professional } \\
\text { activity }\end{array}$} & \multicolumn{4}{|c|}{$\begin{array}{c}\text { Active } \\
86 \%(534)\end{array}$} & \multirow{2}{*}{\multicolumn{2}{|c|}{$\begin{array}{l}\text { Inactive } \\
14 \%(89)\end{array}$}} \\
\hline & $\begin{array}{r}\text { Whi } \\
61\end{array}$ & $\begin{array}{l}\text { collar } \\
326)\end{array}$ & $\begin{array}{l}\text { Blue } \\
39 \%\end{array}$ & & & \\
\hline $\begin{array}{l}\text { Most } \\
\text { common } \\
\text { health } \\
\text { problems }\end{array}$ & $\begin{array}{c}\text { BMl } \\
30.54 \pm 5.38 \\
\mathrm{~kg} / \mathrm{m}^{2}\end{array}$ & $\begin{array}{c}\text { Reproductive } \\
\text { history } \\
2.59 \pm 1.55 \\
\text { births/woman }\end{array}$ & $\begin{array}{c}\text { Hypertension } \\
54 \%(338)\end{array}$ & $\begin{array}{c}\text { IHD } \\
22 \%(138)\end{array}$ & $\begin{array}{c}\text { DM } \\
17 \%(109)\end{array}$ & $\begin{array}{l}\text { Ophthalmic } \\
\text { exam } \\
\text { regularity } \\
2.87 \pm 4.29 \\
\text { years/woman }\end{array}$ \\
\hline
\end{tabular}

DM - diabetes mellitus diagnosed and treated, any type, IHD - ischemic heart disease.

Table II. Comparison of selected parameters between visual subgroups

\begin{tabular}{|c|c|c|c|c|}
\hline Parameter & $\begin{array}{c}\text { Good VA* } \\
\geq 0.8\end{array}$ & $\begin{array}{c}\text { Moderate VA* } \\
0.7-0.3\end{array}$ & $\begin{array}{l}\text { Poor VA* } \\
\leq 0.3\end{array}$ & $P$-value \\
\hline $\begin{array}{l}\text { Participants } \\
n=623\end{array}$ & 417 (67\%) & $186(30 \%)$ & $20(3 \%)$ & \\
\hline TUG & $10.6 \pm 3.1$ & $12.8 \pm 6.1$ & $15.3 \pm 8.8$ & $<0.0001$ \\
\hline IADL & $23.6 \pm 1.5$ & $22.6 \pm 2.9$ & $21.1 \pm 4.8$ & $<0.0001$ \\
\hline Reported falls & $30 \%(124)$ & $41 \%(77)$ & $40 \%(8)$ & $<0.05$ \\
\hline Reported contusions & $18 \%(73)$ & $29 \%(54)$ & $20 \%(4)$ & $<0.01$ \\
\hline
\end{tabular}

*Visual acuity measured on the day of examination (with correction if used during last year and on the day of fall). 
In multivariate logistic regression on probability of falls including IADL, TUG and visual acuity, IADL was found to be an independent prognostic feature $(p=0.025)$ (Figure 1). Visual acuity correlated $(r=-0.13, p<0.0001)$ with falls.

The differences between fallers and non-fallers in visual acuity were significant $\left(\chi^{2}=8.23\right.$, $p$ < 0.05). 293 (70\%) women with good, 109 (59\%) with moderate, and 12 (60\%) with poor vision reported sustaining no falls. The reported contusions also differ $\left(\chi^{2}=-10.3, p<0.01\right)$ among visual subgroups. No contusions were recorded in 344 (82\%) with good, 132 (71\%) with moderate, and $16(80 \%)$ with poor visual acuity.

The near vision acuity in the subgroup of fallers was D0.86 and in non-fallers D0.81. The difference was not statistically significant ( $p=0.341)$. We did not find any association between falls that occurred indoors versus outdoors and visual acuity $(Z=1.71, p=0.085)$. No association between incidence of fractures and visual acuity was found $\left(\chi^{2}=2.84, p=0.24\right)$.

The incidence of falls was not dependent on stereopsis ability $\left(\chi^{2}=1.56, p=0.21\right)$, and stereoscopic vision did not affect the risk of outdoor versus indoor falls $\left(\chi^{2}=1.79, p=0.181\right)$.

The use and type of glasses in faller and nonfaller subgroups were similar. The mean visual acuity in glasses-classified subgroups ranged from 0.7 to 0.9 and was the lowest in subgroup of women wearing bifocal spectacles and without correction. No type of refractive correction affected TUG and IADL. No contact lens use was recorded.

No association between the time of last ophthalmology checkup and visual acuity was found.

Screened main anterior and posterior disturbances are detailed in Table III.

\section{Discussion}

The most important finding of the study is the observation that visual acuity influences the number of falls and functional status. Despite the relationship of visual acuity and number of falls and functional status, fracture prevalence was not increased as a consequence of visual impairment. The fracture risk was probably dependent on several other factors including bone mineral density, and the role of visual impairment was not sufficiently significant in order to reveal its individual influence.

The association of contrast sensitivity with risk of falls is conflicting [17]. Visual field loss as found by Ivers et al. [18] is not as important as visual acuity and is an independent risk factor for falls. Monocular depth perception and dark adaptation were not under evaluation due to the limitation of medical examination time.

In our study, only distance, near visual acuity and stereopsis using standard charts were mea-

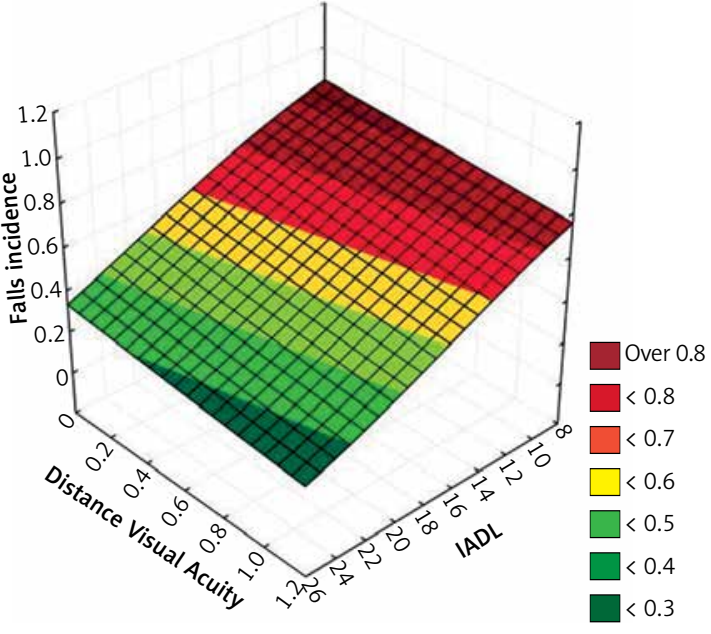

Figure 1. Impact of distance visual acuity and IADL (Instrumental Activities of Daily Living test) outcome measure on risk of falls in elderly women

sured - a quick and repetitive screening test. As pointed out by Harwood [19], overall visual function is more important than any particular ophthalmic diagnosis.

The object of our research was a woman about 65 years of age, obese, and in mental and physical fitness allowing for self-admission to our research. As previously reported, visual acuity in the absence of ocular pathologies remarkably worsens at about the age of 50 [19].

To estimate the physical condition of participants we used the TUG test. Multiple studies have confirmed the content validity, concurrent validity, and predictive validity of that test [14].

We also used the IADL test - which is both subjective and sensitive [20] and previously strongly

Table III. The most common ocular pathologies in the examined sample

\begin{tabular}{|lc|}
\hline Pathology & Prevalence \\
\hline Cataract & $76 \%(472)$ \\
\hline Dry eye syndrome & $48.96 \%(305)$ \\
\hline Lens spectacles (+) & $31.94 \%(199)$ \\
\hline AMD & $11.6 \%(72)$ \\
\hline Glaucoma (treated) & $8.34 \%(52)$ \\
\hline Lens spectacles (-) & $6.9 \%(43)$ \\
\hline Pseudophakia & $5.30 \%(33)$ \\
\hline Glaucoma neuropathy (evident) & $4.82 \%(30)$ \\
\hline Pseudoexfoliation & $4.17 \%(26)$ \\
\hline Diabetic retinopathy & $2.1 \%(13)$ \\
\hline Amblyopia & $2.09 \%(13)$ \\
\hline Degenerative myopia & $1.93 \%(12)$ \\
\hline
\end{tabular}


correlated with risk of falls [21]. These two tests were significantly dependent on age, which was in agreement with their character. It should be mentioned that the scores of these tests could be modulated by a fear of fall reoccurrence [22].

The difference in TUG between fallers and non-fallers was statistically significant. These results did not correspond with the results of Thrane et al. (subgroup of women) [23], where TUG was described as being of low value for clinical assessment of fall risk.

The IADL test in our multifactorial analysis presented an independent prognostic character for risk of falls. Moreover, in our study IADL was the main fall predictor. Corresponding results were reported in the biggest prospective study in women, with mean age close to our participants [21]. It should be mentioned that necessity of self-admission to our study was a very important inclusion factor, which selected participants in good physical condition.

The dexterity tests were mainly dependent on age, even further reducing the role of visual acuity (also correlated with age) in physical condition. Nevertheless, in our analysis the impact of visual impairment on dexterity is not denied but only present in the background.

The dependence between IADL and visual function was previously reported by Owsley et al. [24] in a group of people of similar age. Some functional skills in the IADL test are more or less dependent on vision decline. For the TUG test, vision function is particularly important to keep balance and, as shown in the present research, significantly correlated with the result.

As previously reported, distance visual acuity was correlated with the risk of falls $[21,25]$ Nevertheless, we observed a correlation between good and moderate vision subgroups. The trend of frequency of falls as expected was increasing. The limited number of participants ( 8 fallers and 12 non-fallers) could misrepresent decreased incidence of falls in the poor acuity subgroup.

Vision acuity in our research had no impact on fracture incidence, which is conflicting with the report of De Boer et al. [26].

Near vision acuity, considered the most important in older adults for exploring environmental hazards, presented no significant correlation with the number of falls.

Surprisingly, we found no association between depth perception disturbances and higher risk of falls. Moreover, problems with stereoscopic vision did not increase the frequency of falls in a potentially unpredictable outdoor environment. These data conflict with reports where depth perception was assessed in a similar way $[18,27]$. Nevertheless, other studies have failed to find an association between the risk of falls and depth perception, as assessed by the Randot Stereotest [27].

Our research used the near, not distance, stereotest. The outcome seems to be due to no relation being recorded between near acuity vision and incidences of falls [28]. Probably the distance stereotest is more suitable for fall prediction. The type of spectacles, as reported [29], may modify visual information used for body stabilization and impact falls and fracture risk.

The proportion of subjects who used eyeglasses during a fall, between our group and the group of Ivers et al. [30], was comparable. Nevertheless, we recorded only 3 cases of wearing multifocal eyeglasses, which were previously reported as having the most increased risk of a fall [17]. The mean visual acuity corrected by positive and negative diopter spectacles was comparable and both were classified as good visual acuity.

The visual acuity was not significantly different between subjects who reported a fall with and without glasses. Our data on spectacles use showed no significant changes in visual acuity, dexterity tests scores or moreover in fall frequency.

Several limitations of our study should be mentioned when interpreting the above results. Some falls took place the year period to the measurements of the visual acuity when the habitual current visual function was unknown. Visual acuity decline is a more predictable risk factor for falls than visual acuity [27]. For this assessment a prospective study is optimal.

Contrast sensitivity was not assessed. Nevertheless, visual acuity, contrast sensitivity and depth perception are generally quite closely correlated - poor performance in one implies poor performance in the others [31, 32].

In conclusion, visual acuity influences functional status and number of falls in women aged over 55 years.

\section{Acknowledgments}

Costs of patients' recruitment were covered by local government. The local authority provided all materials necessary for the study including copies of the questionnaire etc. and arranged a location to conduct the study.

\section{Conflict of interest}

The authors declare no conflict of interest.

\section{References}

1. Kannus P, Niemi S, Palvanen M, Parkkari J. Fall-induced injuries among elderly people. Lancet 1997; 350: 1174.

2. Dubljanin-Raspopović E, Marković-Denić L, Matanović D, Grajić $M$, Krstić N, Bumbaširević $M$. Is pre-fracture func- 
tional status better than cognitive level in predicting short-term outcome of elderly hip fracture patients? Arch Med Sci 2012; 8: 115-22.

3. Stevens JA, Corso PS, Finkelstein EA, Miller TR. The costs of fatal and non-fatal falls among older adults. Inj Prev 2006; 12: 290-5.

4. Bączyk G, Opala T, Kleka P. Quality of life in postmenopausal women with reduced bone mineral density: psychometric evaluation of the Polish version of QUALEFFO-41. Arch Med Sci 2011; 7: 476-85.

5. Bączyk G, Opala T, Kleka P, Chuchracki M. Multifactorial analysis of risk factors for reduced bone mineral density among postmenopausal women. Arch Med Sci 2012; 8: 332-41.

6. Muir SW, Gopaul K, Montero Odasso MM. The role of cognitive impairment in fall risk among older adults: a systematic review and meta-analysis. Age Ageing 2012; 41: 299-308.

7. Dhital A, Pey T, Stanford MR. Visual loss and falls: a review. Eye 2010; 24: 1437-46.

8. Squirrell DM, Kenny J, Mawer N, et al. Screening for visual impairment in elderly patients with hip fracture validating a simple bedside test. Eye 2005; 19: 55-9.

9. Pluskiewicz W, Adamczyk P, Czekajlo A, Grzeszczak W, Burak W, Drozdzowska B. Epidemiological data on osteoporosis in women from the RAC-OST-POL Study. Study J Clin Densitom 2012; 15: 308-14.

10. Włodarek D, Głąbska D, Kołota A, et al. Calcium intake and osteoporosis: the influence of calcium intake from dairy products on hip bone mineral density and fracture incidence - a population-based study in women over 55 years of age. Public Health Nutr 2014; 17: 383-9.

11. Drozdzowska B, Wiktor K, Pluskiewicz W. Functional status and prevalence of falls and fractures in population-based sample of postmenopausal women from the RAC-OST-POL Study. Int J Clin Pract 2013; 67: 673-81.

12. Pluskiewicz W, Adamczyk P, Czekajło A, Grzeszczak W, Burak W, Drozdzowska B. Influence of education, marital status, occupation, and the place of living on skeletal status, fracture prevalence, and the course and effectiveness of osteoporotic therapy in women in the RAC OST-POL Study. J Bone Miner Metab 2014; 32: 89-95.

13. Rokicki W, Drozdzowska B, Czekajło A, et al. Common ophthalmic problems of urban and rural postmenopausal women in a population sample of Raciborz district, a RAC-OST-POL Study. Ann Agric Environ Med 2014; 21: 70-4.

14. Podsiadlo D, Richardson S. The Timed "Up \& Go": a test of basic functional mobility for frail elderly persons. J Am Geriatr Soc 1991; 39: 142-8.

15. Lawton MP, Brody EM. Assessment of older people: self-maintaining and instrumental activities of daily living. Gerontologist 1969; 9: 179-86.

16. Mathias S, Nayak USL, Isaacs B. Balance in the elderly patient: the "Get-up and Go" test. Arch Phys Med Rehabil 1986; 67: 387-9.

17. Lord SR, Smith ST, Menant JC. Vision and falls in older people: risk factors and intervention strategies. Clin Geriatr Med 2010; 26: 569-81.

18. Ivers RQ, Cumming RG, Mitchell P, Attebo K. Visual impairment and falls in older adults: the Blue Mountains Eye Study. J Am Geriatr Soc 1998; 46: 58-64.

19. Harwood RH. Visual problems and falls. Age Ageing 2001; 30 Suppl 4: 13-8.

20. Laird R, Studenski S, Perera S, Wallace D. Fall history is an independent predictor of adverse health outcomes and utilization in the elderly. Am J Manag Care 2001; 7: 1133-8.
21. Faulkner K, Cauley J, Studenski S, et al.; Study of Osteoporotic Fractures Research Group. Lifestyle predicts falls independent of physical risk factors. Osteoporos Int 2009; 20: 2025-34.

22. Iglesias CP, Manca A, Torgerson DJ. The health-related quality of life and cost implications of falls in eldery women. Osteoporos Int 2009; 20: 869-78.

23. Thrane G, Joakimsen RM, Thornquist E. The association between timed up and go test and history of falls: the Troms $\varnothing$ study. BMC Geriatr 2007; 7: 1.

24. Owsley C, Sloane M, McGwin G Jr, Ball K. Timed instrumental activities of daily living tasks: relationship to cognitive function and everyday performance assessments in older adults. Gerontology 2002; 48: 254-65.

25. Coleman AL, Stone K, Ewing SK, et al. Higher risk of multiple falls among elderly women who lose visual acuity. Ophthalmology 2004; 111: 857-62.

26. De Boer MR, Pluijm SM, Lips P, et al. Different aspects of visual impairment as risk factors for falls and fractures in older men and women. J Bone Miner Res 2004; 19: 1539-47.

27. Nevitt MC, Cummings SR, Kidd S, Black D. Risk factors for recurrent nonsyncopal falls. A prospective study. JAMA 1989; 261: 2663-8.

28. Friedman SM, Munoz B, West SK, Rubin GS, Fried LP. Falls and fear of falling: which comes first? A longitudinal prediction model suggests strategies for primary and secondary prevention. J Am Geriatr Soc 2002; 50: 1329-35.

29. Lord SR, Dayhew J. Visual risk factors for falls in older people. J Am Geriatr Soc 2001; 49: 508-15.

30. Ivers RQ, Cumming RG, Mitchell P, Simpson JM, Peduto AJ. Visual risk factors for hip fracture in older people. J Am Geriatr Soc 2003; 51: 356-63.

31. Lord SR, Clark RD, Webster IW. Visual acuity and contrast sensitivity in relation to falls in an elderly population. Age Ageing 1991; 20: 175-81.

32. Ensrud KE, Nevitt MC, Yunis C, et al. Correlates of impaired function in older women. J Am Geriatr Soc 1994; 42: 481-9. 


\section{Appendix}

The Lawton Instrumental Activities of Daily Living Scale

1. Ability to use a telephone

3 = Independently $\quad 2$ = Needs some help $\quad 1=$ Does not use a telephone at all

2. Shopping

3 = Independently $\quad 2$ = Needs some help $\quad 1=$ Completely unable to shop

3. Food preparation

$3=$ Independently $\quad 2$ = Needs some help $\quad 1=$ Needs to have meals prepared and served

4. Housekeeping

$3=$ Independently $\quad 2$ = Needs some help $\quad 1$ = Does not participate in any housekeeping tasks

5. Laundry

$3=$ Independently $\quad 2$ = Needs some help $\quad 1=$ All laundry must be done by others

6. Mode of transportation

$3=$ Independently $\quad 2$ = Needs some help $\quad 1=$ Does not travel at all

7. Responsibility for own medications

$3=$ Independently $\quad 2$ = Needs some help $\quad 1=$ Is not capable of dispensing own medication

8. Ability to handle finances

$3=$ Independently $\quad 2$ = Needs some help $\quad 1=$ Incapable of handling money

Final scoring............./24 points 